\title{
O processo de planejamento: uma breve análise de sua importância
}

\author{
Maria Francisca Magalhães Nogueira*
}

\section{Resumo}

Pretende-se neste artigo formular algumas idéias acerca da importância do planejamento como recurso útil para orientar a gestão das instituições na tomada de decisão, bem como alertar para a importância do planejamento da participação dos atores envolvidos e da comunicação como auxiliar ao processo de planejar, implementar e executar. Não se ocupará, no momento, de aprofundar na formulação do processo de planejamento nem de apresentar roteiros metodológicos. Também não se pretende tratar do planejamento nos processos de comunicação.

Palavras-chave: Planejamento-gestão; planejamento - participação; planejamento - comunicação.

\section{Introdução}

Existe um crescente interesse dos comunicadores quanto ao uso do planejamento nas atividades das organizações e, inclusive, nas de comunicação. Muitos profissionais dessa área consideram o planejamento um importante instrumento de intervenção no ambiente, porque possibilita a racionalização de ações e a otimização de recursos. Percebem também que a comunicação pode contribuir para a implementação de planos, programas e projetos, mediante a mobilização de recursos que permitam envolver e integrar pessoas, difundir informações etc.

Em virtude disso, este artigo visa contribuir com os estudantes de comunicação em sua tarefa de abordar as vantagens da utilização de planejamento na vida prática das organizações. Pretende-se, aqui, formular algumas idéias acerca do planejamento - como recurso útil ao reconhecimento de problemas do ambiente, para uma coerente

\footnotetext{
* Maria Francisca Magalhães Nogueira é Mestre em Ciências da Comunicação pela USP e professora da Faculdade de Comunicação e Biblioteconomia da Universidade Federal de Goiás. E-mail: fnogueira@cultura.com.br
}

Comun. Inf., v. 7, n. 1, p.97-103, jan./jun. 2004 
tomada de decisão, e como meio de sistematizar a participação das pessoas - e alertar para a importância da comunicação nesse processo. Não se cogitou, todavia, de aprofundar a abordagem do processo de planejamento nem de apresentar roteiros metodológicos. Também não se tratará do planejamento nos processos de comunicação; apenas se verá a comunicação como auxiliar ao ato de planejamento, implementação e execução.

Algumas organizações, na busca de rápidos resultados para as suas iniciativas, guardam uma visão um pouco distorcida do planejamento e consideram essa iniciativa uma perda de tempo e de recurso. Essa visão, contudo, tem mudado à medida que as relações tornam-se mais complexas e os mercados, mais competitivos. Mas ainda predomina o uso do planejamento tradicional, voltado para a idéia da formalização, quer dizer, do apego ao uso da técnica. Começa a entrar em cena um planejamento que privilegia a presença do ator envolvido, reconhece a existência dos problemas e de suas causas e que não parte imediatamente para a determinação dos objetivos.

\section{O planejamento e a determinação dos problemas: uma questão fundamental}

Ações de menor porte e menos complexas podem ser administradas de modo intuitivo-e, às vezes, de fato o são -, mas, nem por isso, são menos eficazes. $\mathrm{O}$ ato de pensar com método faz parte, ou pelo menos deveria fazer, do perfil de quem ocupa funções diretivas. A complexidade das relações internas e externas às instituições, contudo, aponta para a necessidade de se conhecer o ambiente, as possibilidades e as alternativas viáveis no enfrentamento de problemas. $\mathrm{O}$ reconhecimento dessas necessidades e o estabelecimento de prioridades permitem mobilizar recursos e esforços de forma coerente, precisa e direcionada.

Matus (apud HUERTAS, 1996) explica melhor essa questão ao dizer que o planejamento moderno não se propõe a "adivinhar ou predizer" o futuro, mas a fazer no presente, com base na análise das causas dos problemas, intervenções capazes de influenciar os resultados futuros, para posteriormente propor objetivos a serem alcançados. Assim, a utilização do planejamento torna possível a convivência com as surpresas, pois o que importa são as circunstâncias em que elas Comun. Inf., v. 7, n. 1, p.97-103, jan./jun. 2004 
ocorrem e as peculiaridades do fato em questão, e não a incerteza em si.

A declaração dos problemas passa a ser uma questão fundamental no planejamento não tecnicista, porque considera o fato de toda ação gerar, a curto, médio ou longo prazo, impactos negativos e positivos. Ou seja, qualquer proposição gera custos que refletem nos diversos públicos envolvidos, que, diante desses custos, exigem, em proporções semelhantes, soluções nem sempre conciliáveis. Nesse particular, é bom lembrar que a pesquisa caminha paralelamente ao ato de planejar, mesmo porque a própria elaboração e o desenvolvimento da pesquisa exigem planejamento.

Veja-se, por exemplo, o levantamento dos problemas e suas causas no planejamento do espaço urbano. A demanda pela construção de uma avenida em um determinado local pode implicar crescimento de vendas para alguns comerciantes, mas pode causar a insatisfação de moradores circunvizinhos, em função de um possível aumento do fluxo do trânsito, da insegurança etc., pois em toda situação existe conflito de interesses. Isso implica dizer que a análise da situação obriga que se diferenciem as explicações. Equem as explica deve, conseqüentemente, apontar intervenções com objetivos, às vezes, divergentes ou até antagônicos. No planejamento, segundo Matus (apud HUERTAS 1986, p. 15), "o estrategista não tenta predizer o que fará o adversário; trata apenas de enumerar possibilidades para que possa preparar-se para enfrentá-las. Esse é um caso típico em que o planejamento não repousa na capacidade de predição, mas na capacidade de previsão".

Nessa perspectiva, o planejamento constitui um mecanismo de suporte às decisões macro e micro das instituições, e a comunicação, uma forma de ajudar a viabilizar as propostas, desde a conscientização, passando pela mobilização, até a publicização. No exemplo do planejamento urbano acima citado, a comunicação pode auxiliar a gestão municipal a buscar o consenso para a construção da avenida, prestando esclarecimentos sobre a relação custo-benefício para os moradores, a fim de garantir receptividade ao projeto.

O planejamento constitui um processo que, uma vez adotado, demanda continuidade, flexibilidade, acompanhamento, controle e avaliação permanentes dos esforços empreendidos. Para sua eficaz implementação, não se deve esquecer que a participação dos públicos envolvidos é vital. Além disso, o planejamento possibilita criar, por Comun. Inf., v. 7, n. 1, p.97-103, jan./jun. 2004 
meio da análise de cenários, a consciência das debilidades e também das alternativas que, se bem selecionadas, ajudam o dirigente a elucidar os atores e a estabelecer o rumo a ser seguido.

\section{Planejamento e gestão}

As decisões acertadas apoiam-se em boas interpretações do ambiente e em uma seleção apurada de alternativas possíveis. Nesse aspecto, o processo de planejamento estratégico dá suporte de forma bastante satisfatória à gestão, a fim de que cumpram seus objetivos de orientar a condução das instituições.

Oplanejamento estratégico acentua a preocupação como meio externo e suas influências nas atividades da instituição. Mas variáveis externas, e o que elas pode gerar, nem sempre fizeram parte das preocupações das organizações. Esse modelo de planejamento, o planejamento estratégico, "surgiu como um processo destinado a garantir um ajustamento entre os objetivos e os recursos da organização, e as demandas de um ambiente externo em constante mutação" (ZANIN, 1999, p. 14).

Desse modo, o planejamento estratégico auxilia a instituição a se preparar para enfrentar novos contextos, redefinir o que está sendo realizado, traçar novos rumos, sistematizar novas ações ou eliminar as que não têm mais sentido diante de um novo cenário (ENAP, 1999, p. 35). Planejar estrategicamente faz as empresas conscientizarem-se das oportunidades e das ameaças externas, a fim de traçarem planos coerentes com os seus pontos fortes e fracos.

A grande variedade de empresas - com diferentes filosofias, estilos de administração e de estruturas (em tamanho, tecnologia instalada e número de pessoal), obriga adaptações das diversas metodologias de planejamento existentes. Assim, o planejamento estratégico, pela sua própria natureza, exige um estilo de administração que combine com essa forma de intervenção na realidade das empresas, ou seja, um estilo de administração que tenha uma visão mais globál , uma gestão estratégica.

\section{Planejamento e participação}

É fundamental planejar a participação das pessoas nos vários momentos da elaboração, do desenvolvimento e da execução do plano, do programa ou do projeto. Para despertar o interesse pela

Cómun. Inf., v. 7, n. 1, p.97-103, jan./jun. 2004 
implementação de qualquer tipo de ação, é necessária, contudo, a construção, a priori, de uma atividade constante de escuta, de negociação e de tomada de posição - que pode ser mediante um consenso, um acordo ou uma recusa -, com vistas ao ajuste pragmático entre as normas e as situações, para melhor atingir os objetivos.

$\mathrm{O}$ ato de planejar implica um processo de participação, pois as pessoas envolvidas se responsabilizam tanto pelos riscos das escolhas efetuadas quanto pelos acertos. Um exemplo é o Orçamento Participativo, implantado por diversas administrações municipais no Brasil. No caso de Goiânia, esse programa tem como objetivo a democratização do poder público, mediante uma melhor distribuição dos recursos orçamentários. Por meio dele, a população, representada por seus delegados eleitos, decide onde devem ser aplicados os recursos para investimentos em obras edificadas e revitalizadas, e em infraestrutura, como asfalto etc. Em todas as etapas desse projeto implantação, organização, funcionamento e operacionalização das decisões - a população é conclamada a participar. Um enorme esforço de ações de comunicação garante a sua efetivação.

À medida que se esclarecem para os públicos envolvidos as causas dos problemas e os objetivos estratégicos e operacionais formulados a partir deles, mais legítima será a tomada de decisão e menos arriscada, qualquer iniciativa. Se os objetivos perseguidos são conhecidos, os acordos necessários para a elaboração de um projeto são mais fáceis de serem ajustados. Quanto menos claro estiverem os objetivos para os públicos envolvidos, mais a implementação e os ajustes necessários parecerão arbitrários e sujeitos às variações de humor dos participantes - dirigentes, funcionários etc.

A definição clara de objetivos constitui requisito fundamental para o aperfeiçoamento institucional. A explicitação e a disponibilização de informações sobre os alvos a serem atingidos e as trajetórias a serem percorridas, que evidentemente aperfeiçoam-se e ajustam-se no decorrer dos acontecimentos, constituem, porém, fator importante na manutenção da credibilidade e da confiança na honestidade de propósitos das ações empreendidas. Por isso, alguns cuidados são necessários, não somente na fase de implantação do planejamento, mas também durante todo o processo. É importante municiar as pessoas com conteúdos sobre o próprio planejamento, com informações que

Comun. Inf., v. 7, n. 1, p.97-103, jan./jun. 2004 


\section{2}

serão incorporadas ao documento - plano, programa ou projeto - e com outras que deverão ser buscadas mediante o levantamento de dados. Também é importante informar as pessoas sobre quem são os coordenadores do planejamento e os atores relevantes que integrarão todo o processo.

É evidente também que a natureza da participação tem relação direta com o sentido de valoração que lhe for dado. Mas não se travará essa discussão no âmbito deste artigo. Apenas para ilustrar, recordase o que diz Sánchez (2001, p. 41) sobre o sentido da participação. Para esse autor, ela pode ser efetiva ou representada, passiva ou ativa, legitimadora ou transformadora de projetos oficiais.

Não constitui tarefa de fácil realização a construção de projetos consensuados ou que, pelo menos, se aproximem das necessidades e dos desejos daqueles que serão favorecidos ou desfavorecidos. Segundo Gandin (1994, p. 57), constituem dificuldades desde a "resistência dos que perderiam privilégios, até a falta de metodologias adequadas, passando pela falta de compreensão e de desejo de realizar [o projeto e, ainda,] pelo constrangimento exercido pelas estruturas existentes".

\section{Conclusão}

Planejar pode ser uma tarefa simples ou complexa, dependendo da problemática em questão. Quanto mais complexo o problema e suas causas, mais necessário é o compromisso da administração superior, que tem poder de decisão para intervir de fato na realidade. $\mathrm{O}$ ato de planejar também implica comprometimento das pessoas envolvidas e, por conseguinte, da comunicação, uma aliada nas várias etapas do processo, sobretudo no esclarecimento e na sensibilização dos envolvidos, na difusão de informações a ele relacionadas etc.

A opção por um ou outro modelo de planejamento depende da necessidade da organização em determinados momentos. Mas ressaltase que a importância está no processo de planejamento em si, que Gandin (1994, p. 58) conceitua nesses termos: "Planejar é utilizar o mesmo método com a diferença que, ao invés de contentar-se com o conhecimento e a explicação da realidade, o planejamento implica em transformar a realidade existente e construir uma nova".

Comun. Inf., v. 7, n. 1, p.97-103, jan./jun. 2004 


\section{Abstract:}

The purpose of this study is to discuss some ideas about the importance of planning as a useful resource for guiding management of institutions in their decision making. It also alerts for the process of planning, implementing and executing. It is not aiming, at to deepen into the formulation of the process of planning, nor to present methodological guides. It does no intend either to ideal with the planning of the communication process.

Keywords: planning-management; planning-participation; planningcommunication

\section{Referências}

ENAP. Curso de Planejamento Estratégico. Brasília: Escola Nacional de Administração Pública, 1999.

GANDIN, Danilo. A prática do planejamento participativo: na educação e em outras instituições, grupos e movimentos dos campos cultural, social, político, religioso e governamental. Petrópolis: Vozes, 1994.

HUERTAS, Franco. O método PES: entrevista com Matus. São Paulo: Fundap, 1996.

SÁNCHEZ, Fernanda. A reinvenção das cidades na virada de século: agentes, estratégias e escalas de ação política. Revista de Sociologia e Política. Universidade Federal do Paraná, número 16, p. 31-49, 2001. ZANIN, Rogério Fortes et al. Planejamento estratégico - UFSM: referencial teórico. Universidade Federal de Santa Maria. Pró-Reitoria de Planejamento. Santa Maria, 1999.

Comun. Inf., v. 7, n. 1, p.97-103, jan./jun. 2004 